\title{
EuGMS Task and Finish group on Fall-Risk-Increasing Drugs (FRIDs): Position on Knowledge Dissemination, Management, and Future Research
}

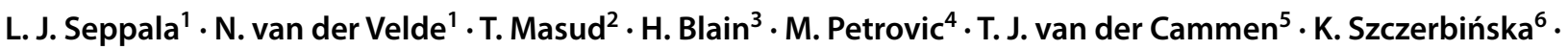

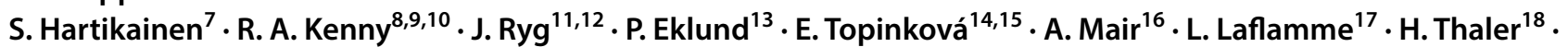 \\ G. Bahat ${ }^{19} \cdot$ M. Gutiérrez-Valencia ${ }^{20} \cdot M A$ Caballero-Mora ${ }^{21} \cdot$ F. Landi ${ }^{22} \cdot M$. H. Emmelot-Vonk ${ }^{23}$ on behalf of the \\ EuGMS Task and Finish Group on Fall-Risk-Increasing Drugs · A. Cherubini ${ }^{24} \cdot$ J. P. Baeyens ${ }^{25,26} \cdot$ A. Correa-Pérez ${ }^{27}$. \\ A. Gudmundsson ${ }^{28,29} \cdot$ A. Marengoni ${ }^{30} \cdot$ D. O'Mahony ${ }^{31,32} \cdot$ N. Parekh ${ }^{33} \cdot$ F. E. Pisa ${ }^{34,35} \cdot$ C. Rajkumar ${ }^{36} \cdot$ M. Wehling $^{37}$. \\ G. Ziere ${ }^{38,39}$ on behalf of the EuGMS Special Interest Group on Pharmacology
}

Published online: 11 February 2019

(c) The Author(s) 2019

\section{Key summary points}

Falls are under-recognized as adverse drug events.

Healthcare professionals are reluctant to withdraw fall-risk-increasing medications.

The EuGMS Task and Finish group on fall-risk-increasing drugs (FRIDs) proposes in this paper its recommendations on dissemination of knowledge about, management of, and future research on FRIDs.

\begin{abstract}
Falls are a major public health concern in the older population, and certain medication classes are a significant risk factor for falls. However, knowledge is lacking among both physicians and older people, including caregivers, concerning the role of medication as a risk factor. In the present statement, the European Geriatric Medicine Society (EuGMS) Task and Finish group on fall-risk-increasing drugs (FRIDs), in collaboration with the EuGMS Special Interest group on Pharmacology and the European Union of Medical Specialists (UEMS) Geriatric Medicine Section, outlines its position regarding knowledge dissemination on medication-related falls in older people across Europe. The EuGMS Task and Finish group is developing educational materials to facilitate knowledge dissemination for healthcare professionals and older people. In addition, steps in primary prevention through judicious prescribing, deprescribing of FRIDs (withdrawal and dose reduction), and gaps in current research are outlined in this position paper.
\end{abstract}

\section{Introduction}

L. J. Seppala and N. van der Velde are shared first co-authors.

T. Masud, J. Ryg, E. Topinková and G. Bahat also on behalf of the European Union of Medical Specialists (UEMS)-Geriatric Medicine Section.

This article is co-published in the journals Drugs \& Aging [https ://doi.org/10.1007/s40266-018-0622-7] and European Geriatric Medicine [https://doi.org/10.1007/s41999-019-00162-8].

N. van der Velde

n.vandervelde@amc.uva.nl

Extended author information available on the last page of the article
Falls in older people are a significant public health priority because of their high prevalence, related injuries, reduced quality of life for fallers, and the associated economic burden [1]. One-third of people aged $\geq 65$ years fall at least once yearly, and $20 \%$ of these falls lead to severe injuries [2]. Among older people, approximately 40,000 fatal falls are reported in the EU annually [3]. Between 0.85 and $1.50 \%$ of the total healthcare expenditure in Europe, North America, and Australia [4] are fall-related costs, meaning these injuries are among the 20 most expensive medical conditions among community-dwelling older people [5]. Medications are crucial risk factors for falls, and withdrawal of 
fall-risk-increasing drugs (FRIDs) is an effective intervention to prevent falls [6]. Moreover, falls, widely acknowledged as a geriatric syndrome, are also established adverse drug events (ADEs). It is estimated that ADEs lead to 8.6 million unplanned hospital admissions in Europe annually, and $50 \%$ of these are preventable [7]. A total of $70 \%$ of ADEs affect patients aged $>65$ years taking five or more medicines [7].

Despite the evidence of the association between medications and falls, awareness of this topic is lacking among physicians and older people and their caregivers [8-11]. Indeed, physicians and patients commonly overestimate the benefits of medications and underestimate the potential harms [12]. Furthermore, many physicians perceive the uncertainty about the consequences of withdrawing FRIDs as challenging and uncomfortable [9]. Older patients also have concerns about deprescribing, such as fearing a relapse of their condition, and concerns about adverse drug withdrawal reactions [13, 14]. Consequently, limited knowledge and skills in FRIDs withdrawal and reluctance to withdraw mean avoidable injurious events and other adverse outcomes related to falls continue.

In this position statement, the European Geriatric Medicine Society (EuGMS) Task and Finish group on FRIDs, in collaboration with the EuGMS Special Interest Group on Pharmacology and the European Union of Medical Specialists (UEMS)-Geriatric Medicine Section, outline (1) the preferential strategies for knowledge dissemination to older people and professionals on FRIDs, (2) recommendations for the management of FRIDs, and (3) recommendations for future research on medication-related falls.

\section{Prevention of Medication-Related Falls}

Psychotropic and cardiovascular medicines are the most important FRID classes. The recent systematic reviews and meta-analyses by the EuGMS Task and Finish group on FRIDs confirmed the association between psychotropics (antidepressants [selective serotonin reuptake inhibitors, tricyclic antidepressants], antipsychotics, benzodiazepines) and fall risk [15]. Moreover, consistent associations with falls were reported for loop diuretics, antiepileptics, opioids, and polypharmacy (four or more medications) $[16,17]$. Digitalis, non-selective beta-blocking agents, antiarrhythmics, diuretics in general, antihypertensives, anticholinergics, non-steroidal anti-inflammatory drugs, analgesics, laxatives, long-term proton pump inhibitors, and antiplatelets are also possible FRIDs [16, 17]. These high-risk medications are widely prescribed for older people. Almost $90 \%$ of older adults with dizziness visiting their general practitioner use at least one FRID [18]. Approximately $60 \%$ of older adults admitted to hospital because of a fall use one or more FRID, and $36 \%$ use five or more medications [19].

Preventing fall incidents by identifying and reducing the use of risk-increasing medications is an essential and effective component of a multifactorial fall-risk-management approach. A Cochrane review in 2012 summarized the randomized controlled trials (RCTs) of interventions to reduce falls in community-dwelling older people [6]. Gillespie et al. reported that withdrawal of psychotropics is effective in reducing fall rates and that a prescribing-modification program for primary care physicians can reduce the risk of falling in older people [6]. In addition, applying the FORTA (Fit fOR The Aged) list, a positive-negative medication-optimization approach, was effective in reducing fall rates in hospitalized geriatric patients [20]. Furthermore, the implementation of STOPP/START (Screening Tool for Older People's potentially inappropriate Prescriptions/Screening Tool to Alert doctors to Right Treatment) criteria significantly reduced the number of falls in a chronic care geriatric facility [21]. The 2010 American Geriatrics Society/British Geriatrics Society joint guideline [22] and the World Health Organization (WHO) Integrated Care for Older People guideline [23] recommend that individuals at high risk of falling, identified by screening, should be assessed for risk factors, including medication. The medication review should include an assessment of drug duplicates and drug-drug interactions. The American Geriatrics Society/British Geriatrics Society joint guideline further states that minimizing medications is an important component of the multifactorial intervention and that, if discontinuation of a FRID is not possible, dose reduction should be considered.

Moreover, about $20 \%$ of falls result in serious injuries, such as fragility fractures and intracranial bleeding, and death [2]. Drug-induced osteoporosis is a growing health problem, and many commonly prescribed medications contribute to significant bone loss and fractures [24]. In the overall risk assessment of drugs contributing to falls and their serious consequences, the list of drugs known to enhance skeletal fragility (e.g., glucocorticoids, antiepileptics, gonadotropin-releasing hormone agonists and aromatase inhibitors) or bleeding (e.g., anticoagulants and antiplatelet therapy) should also be taken into account $[25,26]$.

Taken together, the EuGMS Task and Finish group on FRIDs

1. advocates better recognition of the role of FRIDs in fall incidents and the importance of knowledge dissemination on this topic,

2. advocates better research quality in the future to gain improved insight on FRIDs and their effective and safe withdrawal measures,

3. recommends systematically checking for a history of falls and high risk of falling before prescribing FRIDs, 
4. supports and encourages better implementation of the 2010 American Geriatrics Society/British Geriatrics Society joint guideline recommendations into practice, including medication review for all patients with an acute fall, recurrent falls in the past year, or problems with walking or balance,

5. supports the EuGMS Falls and Fracture Special Interest Group recommendation that healthcare professionals screen older people, at least annually, for risk of falling [27], suggesting, in addition, a medication review for all older people every year, and every 6 months if the older individual is frail or vulnerable.

\section{How to Reduce the Use of Fall-Risk-Increasing Drugs (FRIDs)?}

The first step in reducing the harm caused by FRIDs is to prevent their inappropriate use in the older population. Tools for detection of inappropriate prescribing, such as the Medication Appropriateness Index [28-30], have been developed to support a physician's clinical judgment. It should be noted that listing approaches such as START/ STOPP or FORTA include aspects of fall risk reduction, as FRIDs are mostly highlighted as causative factors. Interventional trials have shown that these systematic drug-optimization strategies can reduce drug side effects [31, 32], including falls [20]. However, no single ideal tool exists currently, and the choice of tool may rely on the purpose of use and availability of data $[30,33]$. Such a tool should be not only well-designed and comprehensive but also practical to be implemented in everyday clinical practice [30, 33].

When reviewing a patient's medication lists, withdrawal of FRIDs can be performed safely in older people at high risk of falls [34]. Withdrawal can involve immediate cessation of medication or a stepwise process depending on the medication to be withdrawn. For medications to be withdrawn in a stepwise manner, specific withdrawal guidelines are available in national formularies [35]. Examples of medications to be stopped gradually are benzodiazepines, opioids, antidepressants, and betablockers. The EuGMS Task and Finish group on FRIDs proposes the decision tree shown in Fig. 1 for withdrawal of FRIDs [36, 37].

\section{Multidisciplinary Approach}

Healthcare professionals other than physicians, such as pharmacists, nurses, physiotherapists, occupational therapists, and nutritionists, play an important role in a multidisciplinary approach to prevention of drug-related falls. The American STEADI (Stopping Elderly Accidents,
Deaths \& Injuries) initiative concludes that a pharmacist can screen patients to determine fall risk using a standardized protocol, perform a medication review, and recommend vitamin D supplementation when appropriate [38]. Pharmacist-led medication improvement programs have led to improved medication use and greater discontinuation of high-risk medications [39, 40]. The pharmacist can arrange a fall risk assessment with a primary care team if the patient is at risk of falling, as identified through screening. In a thorough medication review, the pharmacist, in close collaboration with the multidisciplinary team and particularly the physician, can screen for FRIDs, assess the patient's pharmacotherapy management, formulate the patient's medication management plan, and educate the patient about fall-prevention strategies and medication changes [38]. The EuGMS Task and Finish group on FRIDs supports the recommendation of the STEADI initiative to promote greater involvement of a clinical pharmacist in the medication review process [38]. Similarly, nurses are well positioned to recognize a change in an older patient's risk of falling and communicate this to the other multiprofessional team members [41, 42]. Nurses can drive organizational change toward falls prevention through a team approach by considering planning, implementing, and evaluating a falls-prevention program that incorporates identification and minimization of FRIDs [41, 42].

\section{Barriers to Effective Medication Withdrawals}

Although withdrawal of FRIDs has been reported to be effective in reducing fall rates [6], the majority of older people do not have their medication checked or changed after a recent fall. An American survey found that only $3.5 \%$ of older people had their medication changed after a fall [43]. Furthermore, an observational study in primary care reported that withdrawal of FRIDs was performed in only $11.7 \%$ of seniors with a clear indication (dizziness) for withdrawal [18].

Lack of knowledge and skills are among the major barriers to providers adopting and implementing effective fall-prevention approaches [44]. These skills are not sufficiently acquired during studies. Physician trainees perceive difficulties dealing with multimorbidity, atypical disease presentations, and polypharmacy [45]. All these components are relevant for the recognition of and possible preventive interventions for medication-related falls.

For older people, a lack of perception about fall risk is a major barrier to patient participation in fall-prevention programs [46]. Older people often have an inappropriately positive perception of the possible consequences of a fall 
Fig. 1 Decision tree for management of fall-risk-increasing drugs (FRIDs)

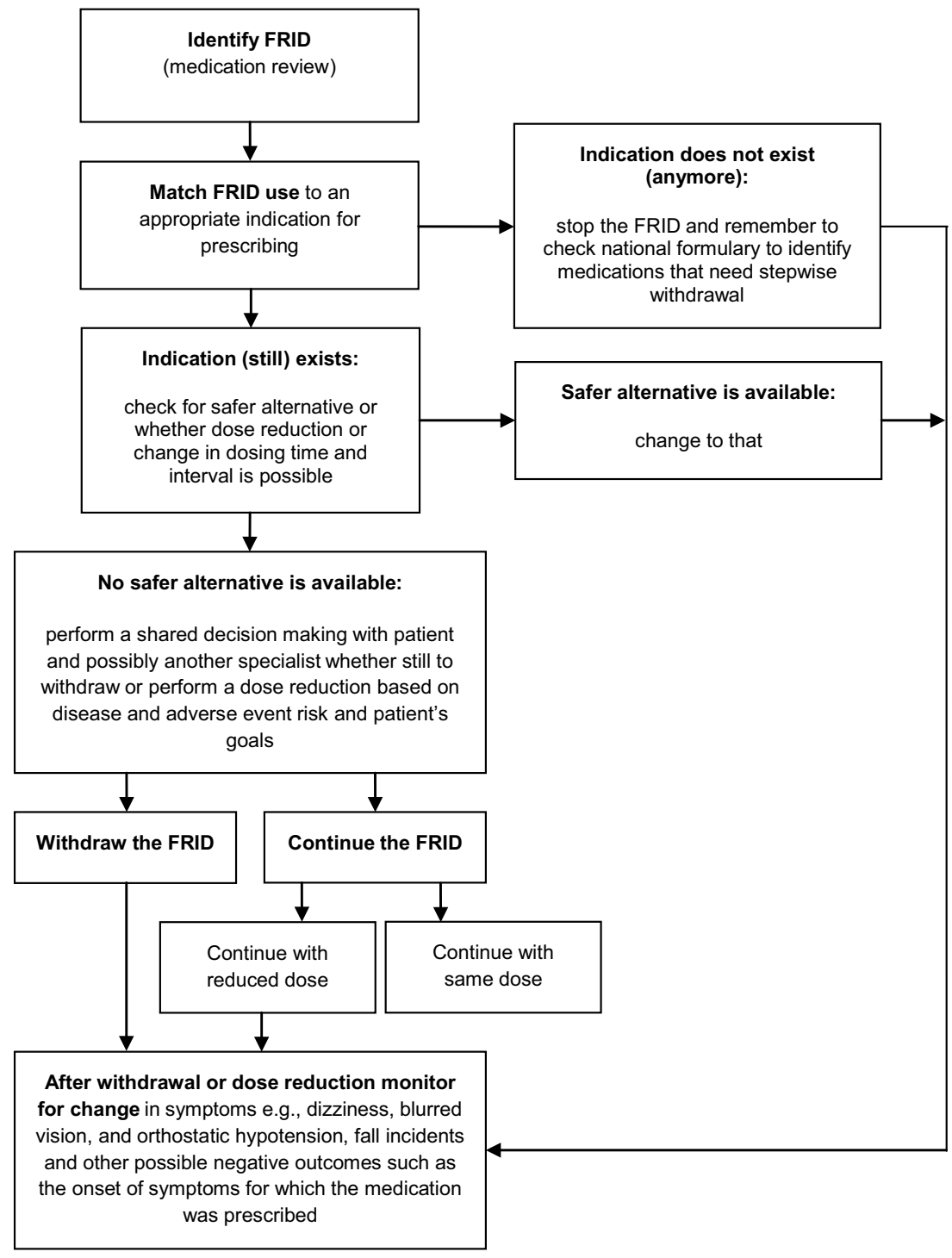

[47]. Moreover, awareness of medication management as an important fall-prevention strategy is low among older adults [8]. In addition, older people often do not consider medications as a possible risk factor for falls and struggle to present their medication-related problem to the physician [9]. Medication use is usually perceived as an unavoidable necessity [48].

\section{Improving Medication Withdrawal: Disseminating Knowledge}

To overcome the lack of knowledge and skills among physicians and the poor awareness among older adults, the EuGMS Task and Finish group on FRIDs makes the following recommendations.
1. The European Undergraduate Curriculum in Geriatric Medicine should be mandatory in the education of all medical students. The curriculum states that graduates should know the pathophysiology, diagnosis, assessment, management, and preventive strategies for falls [49]. In addition, the EuGMS Task and Finish group on FRIDs is developing an English-language educational video regarding medication-related falls, which will be available through the website of the EuGMS Task and Finish group on FRIDs.

2. Knowledge should be disseminated among practising physicians and other healthcare professionals through seminars, brochures, web pages, and apps; by enlisting opinion leaders to influence colleagues; and by conducting educational outreach visits [50]. The Task and Finish group is developing English-language e-learning material about FRIDs and falls. We encourage Euro- 
pean countries to adopt and test the material, translating where necessary (Table 1 ).

3. Public awareness and knowledge should be enhanced through media attention, educational material for older people, brochures, posters, and web pages [50]. Improving the health literacy of older adults could be a valuable intervention to reduce the harms associated with FRIDs [51]. For older people, we are designing an Englishlanguage leaflet about FRIDs for public dissemination. We encourage European countries to adopt and test the material, translating where appropriate (Table 1).

4. A European FRIDs list should be created. The EuGMS Task and Finish group plans to develop a FRIDs list to be used as a fall-prevention tool.

\section{"Gaps" in Current Research}

The evidence for medications as risk factors for falls is based on observational studies. To date, RCTs have only rarely collected falls as adverse events [15-17]. The EuGMS Task and Finish group on FRIDs recommends that falls and fallrelated injuries should be actively sought as adverse events in RCTs when applying for a license for a new drug to enter the market [52]. In addition, we advocate that older people, including the "oldest old," are adequately represented in RCTs as they are the primary users of medications [52]. Further research is required to establish the lower limit for blood-pressure reduction using antihypertensives in frailer older adults, after which the harms of falls and other adverse events outweigh the cardiovascular benefits.

Most of the published observational studies on medications as risk factors for falling have several quality issues, including accurate medication and falls ascertainment as well as problems with confounder variables [15-17]. The EuGMS Task and Finish group on FRIDs supports the following items to increase the quality of observational studies further $[53,54]$.

1. Population Studies should be conducted in populations with different characteristics to assess whether different populations have dissimilar medication-related fall risks.
The characteristics of the population, such as frailty, should be precisely defined.

2. Outcome We support the fall definition and fall ascertainment recommended by The Prevention of Falls Network Europe [55]. A fall should be defined as "an unexpected event in which the participant comes to rest on the ground, floor or lower level," and falls should be recorded prospectively using daily recording.

3. Medication

(a) The studied target medication should be precisely defined, preferably using the WHO-recommended anatomical therapeutic chemical (ATC) medication classification system. This will enable clinicians and researchers to harmonize datasets, to compare results for the same medication between different studies, and to summarize evidence through systematic reviews and meta-analyses.

(b) As different pharmacological subgroups and individual agents in these subgroups might have different fall-risk-increasing properties, these subgroups and chemical substances should be assessed in future studies.

(c) Collecting data on medication use only at baseline in studies makes it likely that medication use by participants may change during follow-up. The aim should be to perform the medication (ATC code, dosage, duration of use) data collection, including over-the-counter medications, at a relevant time interval for the fall to minimize bias in the studies.

(d) To date, the Drug Burden Index, which evaluates the cumulative burden of sedatives and anticholinergics, and different measures of anticholinergic burden have been associated with increased fall risk [16]. However, whether dosage is an important factor in falls caused by other medication groups should be evaluated in the future. In addition, investigation of whether fall risks increase after initiation of therapy compared with chronic use is warranted.

(e) If falls are evaluated as adverse events in observational studies, then validated criteria such as that

Table 1 Steps in translating educational material

1. Check the EuGMS Task and Finish group on FRIDs webpage (http://www.eugms.org/research-cooperation/special-interest-groups/falls-andfractures.html) to see whether the educational material is available in your language

2. If not available in your language: The recommended way of translating the material is to use two translators, then conduct a pilot test among older adults, correct the translation, test again with older adults and then perform a reverse translation to confirm that the final version is consistent with the original version

3. If you perform a translation, contact us so we may make the material publically available through the EuGMS website 
of the WHO-Uppsala Monitoring Centre (UMC) and a rigorous assessment process for rating the causality of the event should be used [56,57].

4. Confounding factors Confounders should be carefully chosen. Besides the typical confounders such as comorbidities, indicators of frailty, and other factors related to the fall risk, drug indication, and concurrent medications should be taken into account as possible confounding variables.

5. Other issues Combination drugs and therapies and drugdrug interactions and their effect on fall risk have not been actively investigated in studies.

\section{Conclusion}

The EuGMS Task and Finish group on FRIDs advocates more attention to dissemination of knowledge regarding FRIDs, increased insight, and improved practice, including the following:

- encouraging systematic judicious deprescribing by including the following steps: recognizing a possible indication for the medication, searching for a safer alternative, performing shared decision making, and monitoring for symptoms after stopping the FRID.

- disseminating knowledge to healthcare workers, healthcare students, and the older population, which could enable a more active role for older individuals in shared decision making. Medication-related falls should be part of the curriculum for all healthcare students.

- creating a European FRIDs list to be used as a fall-prevention tool.

- increasing knowledge about the risk of falls associated with therapeutic classes and individual medications through well-designed observational studies and RCTs.

The EuGMS Task and Finish group on FRIDs emphasizes that effective knowledge dissemination and improved withdrawal of FRIDs, as a result of that knowledge dissemination, is likely to reduce the number of fall injuries [50,58].

\section{Compliance with Ethical Standards}

Funding This study was supported by the Clementine Brigitta Maria Dalderup fund, which is an Amsterdam University fund. The sponsor played no part in the design or preparation of this paper.

Conflict of interest Martin Wehling was employed by AstraZeneca R\&D, Mölndal, as Director of Discovery Medicine (= translational medicine) from 2004 to 2006 while on sabbatical leave from his professorship at the University of Heidelberg. After returning to this position in January 2007, he received lecturing and consulting fees from
Bristol Myers, Bayer, LEO, Boehringer-Ingelheim, Mundipharma, Novartis, Pfizer, Roche, AstraZeneca, Allergan, Polyphor, Helsinn, Sanofi-Aventis, Shire, Otsuka, Lilly, Berlin-Chemie, and Novo-Nordisk. The work of Eva Topinkova was partially supported by grant no. 16-33463A from the Czech Ministry of Health, Czech Republic. LJS, NvdV, TM, HB, MP, TJvdC, KS, SH, RAK, JR, PE, AMair, LL, HT, GB, MG-V, MAC-M, FL, MHE-V, AC, JPB, AC-P, AG, AM, DO, NP, FEP, CR, GZ have no conflicts of interest that are directly relevant to the content of this article.

Ethical approval This article does not contain any studies with human participants performed by any of the authors.

Informed consent For this type of study formal consent is not required.

Open Access This article is distributed under the terms of the Creative Commons Attribution 4.0 International License (http://creativeco mmons.org/licenses/by/4.0/), which permits unrestricted use, distribution, and reproduction in any medium, provided you give appropriate credit to the original author(s) and the source, provide a link to the Creative Commons license, and indicate if changes were made.

\section{References}

1. Hartholt KA, van Beeck EF, Polinder S, van der Velde N, van Lieshout EM, Panneman MJ, et al. Societal consequences of falls in the older population: injuries, healthcare costs, and long-term reduced quality of life. J Trauma. 2011;71:748-53.

2. Centers for Disease Control and Prevention. Home and Recreational Safety. Important facts about falls. 2017. http://www.cdc. gov/homeandrecreationalsafety/falls/adultfalls.html Accessed 1 May 2018.

3. EuroSafe. EuroSafe. Injuries in the European Union, Summary on injury statistics 2012-2014. 2016. http://www.bridge-health.eu/ sites/default/files/EuropeSafe_Master_R4_SinglePage_12102 016\%20\%281\%29.pdf. Accessed 1 Mar 2018.

4. Heinrich S, Rapp K, Rissmann U, Becker C, König H-H. Cost of falls in old age: a systematic review. Osteoporos Int. 2010;21:891-902.

5. Carroll NV, Slattum PW, Cox FM. The cost of falls among the community-dwelling elderly. J Manag Care Pharm. 2005;11:307-16.

6. Gillespie LD, Robertson MC, Gillespie WJ, Sherrington C, Gates $\mathrm{S}$, Clemson LM, et al. Interventions for preventing falls in older people living in the community. Cochrane Database Syst Rev. 2012;2012:Cd007146.

7. Mair AF-LF, Alonso A, Harrison C, Hurding S, Kempen T, Kinnear M, Michael N, McIntosh J, Wilson M. The Simpathy consortium. Polypharmacy management by 2030: a patient safety challenge. 2017. http://www.simpathy.eu/resources/publicatio ns/simpathy-project-reference-book. Accessed 14 Apr 2018.

8. Laing SS, Silver IF, York S, Phelan EA. Fall prevention knowledge, attitude, and practices of community stakeholders and older adults. J Aging Res. 2011;2011:9.

9. Bell HT, Steinsbekk A, Granas AG. Factors influencing prescribing of fall-risk-increasing drugs to the elderly: a qualitative study. Scand J Prim Health Care. 2015;33:107-14.

10. Bell HT, Steinsbekk A, Granas AG. Elderly users of fall-riskincreasing drug perceptions of fall risk and the relation to their drug use-a qualitative study. Scand J Prim Health Care. 2017;35:247-55. 
11. Gillespie R, Mullan J, Harrison L. Managing medications: the role of informal caregivers of older adults and people living with dementia. A review of the literature. J Clin Nurs. 2014;23:3296-308.

12. Hoffmann TC, Del Mar C. Clinicians' expectations of the benefits and harms of treatments, screening, and tests: a systematic review. JAMA Intern Med. 2017;177:407-19.

13. Reeve E, Low L-F, Hilmer SN. Beliefs and attitudes of older adults and carers about deprescribing of medications: a qualitative focus group study. Br J General Pract. 2016;66:e552-60.

14. Reeve E, To J, Hendrix I, Shakib S, Roberts MS, Wiese MD. Patient barriers to and enablers of deprescribing: a systematic review. Drugs Aging. 2013;30:793-807.

15. Seppala LJ, Wermelink A, de Vries M, Ploegmakers KJ, van de Glind EMM, Daams JG, et al. Fall-risk-increasing drugs: a systematic review and meta-analysis: II. Psychotropics. J Am Med Dir Assoc. 2018;19(371):e11-7.

16. Seppala LJ, van de Glind EMM, Daams JG, Ploegmakers KJ, de Vries M, Wermelink A, et al. Fall-risk-increasing drugs: a systematic review and meta-analysis: III. Psychotropics. J Am Med Dir Assoc. 2018;19(372):e1-8.

17. de Vries M, Seppala LJ, Daams JG, van de Glind EMM, Masud $\mathrm{T}$, van der Velde N, et al. Fall-risk-Increasing drugs: a systematic review and meta-analysis: I. cardiovascular drugs. J Am Med Dir Assoc. 2018;19:371e1-e9.

18. Stam H, Harting T, van der Sluijs M, van Marum R, van der Horst $\mathrm{H}$, van der Wouden JC, et al. Usual care and management of fall risk increasing drugs in older dizzy patients in Dutch general practice. Scand J Prim Health Care. 2016;34:164-70.

19. Laflamme L, Monarrez-Espino J, Johnell K, Elling B, Moller J. Type, number or both? A population-based matched casecontrol study on the risk of fall injuries among older people and number of medications beyond fall-inducing drugs. PLoS One. 2015;10:e0123390.

20. Michalek C, Wehling M, Schlitzer J, Frohnhofen H. Effects of "Fit fOR The Aged" (FORTA) on pharmacotherapy and clinical endpoints-a pilot randomized controlled study. Eur J Clin Pharmacol. 2014;70:1261-7.

21. Frankenthal D, Lerman Y, Kalendaryev E, Lerman Y. Intervention with the screening tool of older persons potentially inappropriate prescriptions/screening tool to alert doctors to right treatment criteria in elderly residents of a chronic geriatric facility: a randomized clinical trial. J Am Geriatr Soc. 2014;62:1658-65.

22. Panel on Prevention of Falls in Older Persons, American Geriatrics Society and British Geriatrics Society. Summary of the updated american geriatrics society/british geriatrics society clinical practice guideline for prevention of falls in older persons. J Am Geriatr Soc. 2011;59:148-57.

23. World health organization. Integrated care for older people: guidelines on community-level interventions to manage declines in intrinsic capacity. 2017. http://www.who.int/ageing/publicatio ns/guidelines-icope/en/. Accessed 2 May 2018.

24. Mirza F, Canalis E. Management of endocrine disease: secondary osteoporosis: pathophysiology and management. Eur J Endocrinol. 2015;173:R131-51.

25. Nguyen KD, Bagheri B, Bagheri H. Drug-induced bone loss: a major safety concern in Europe. Expert Opin Drug Saf. 2018;17:1005-14.

26. van den Brand CL, Tolido T, Rambach AH, Hunink MG, Patka $\mathrm{P}$, Jellema K. Systematic review and meta-analysis: is pre-injury antiplatelet therapy associated with traumatic intracranial hemorrhage? J Neurotrauma. 2017;34:1-7.

27. Blain H, Masud T, Dargent-Molina P, Martin FC, Rosendahl E, van der Velde N, et al. A comprehensive fracture prevention strategy in older adults: the European union geriatric medicine society (EUGMS) statement. Eur Geriatr Med. 2016;7:519-25.
28. Hanlon JT, Schmader KE. The medication appropriateness index at 20: where it started, where it has been, and where it may be going. Drugs Aging. 2013;30:893-900.

29. Parekh N, Page A, Ali K, Davies K, Rajkumar C. A practical approach to the pharmacological management of hypertension in older people. Ther Adv Drug Saf. 2017;8:117-32.

30. Kaufmann CP, Tremp R, Hersberger KE, Lampert ML. Inappropriate prescribing: a systematic overview of published assessment tools. Eur J Clin Pharmacol. 2014;70:1-11.

31. Wehling M, Burkhardt H, Kuhn-Thiel A, Pazan F, Throm C, Weiss $C$, et al. VALFORTA: a randomised trial to validate the FORTA (Fit fOR The Aged) classification. Age Ageing. 2016;45:262-7.

32. O'Connor MN, O'Sullivan D, Gallagher PF, Eustace J, Byrne S, O'Mahony D. Prevention of hospital-acquired adverse drug reactions in older people using screening tool of older persons' prescriptions and screening tool to alert to right treatment criteria: a cluster randomized controlled trial. J Am Geriatr Soc. 2016;64:1558-66.

33. Petrovic M, Gnjidic D, Tommelein E, Boussery K. Pharmacotherapy. In: Roller-Wirnsberger R, Singler K, Polidori M, editors. Learning geriatric medicine. Cham: Springer; 2018. p. 219-35.

34. Iyer S, Naganathan V, McLachlan AJ, Le Conteur DG. Medication Withdrawal trials in people aged 65 years and older. Drugs Aging. 2008;25:1021-31.

35. Joint Formulary Committee. British national formulary. 2018. https://bnf.nice.org. Accessed 14 May 2018.

36. Scott IA, Hilmer SN, Reeve E, et al. Reducing inappropriate polypharmacy: the process of deprescribing. JAMA Intern Med. 2015;175:827-34.

37. Garfinkel D, Mangin D. Feasibility study of a systematic approach for discontinuation of multiple medications in older adults: addressing polypharmacy. Arch Intern Med. 2010;170:1648-54.

38. Karani MV, Haddad Y, Lee R. The role of pharmacists in preventing falls among America's older adults. Front Public Health. 2016;4:250.

39. Meredith S, Feldman P, Frey D, Giammarco L, Hall K, Arnold K, et al. Improving medication use in newly admitted home healthcare patients: a randomized controlled trial. J Am Geriatr Soc. 2002;50:1484-91.

40. Blalock SJ, Casteel C, Roth MT, Ferreri S, Demby KB, Shankar $\mathrm{V}$. Impact of enhanced pharmacologic care on the prevention of falls: a randomized controlled trial. Am J Geriatr Pharmacother. 2010;8:428-40.

41. Preventing in-patient falls. The nurse's pivotal role. Nursing. 2018;2017(47):30-1.

42. Australian Commission on Safety and Quality in Health Care. Preventing falls and harm from falls in older people: best practice guidelines for Australian residential aged care facilities. 2009. Accessed 26 Oct 2018.

43. Boyd R, Stevens JA. Falls and fear of falling: burden, beliefs and behaviours. Age Ageing. 2009;38:423-8.

44. Tinetti ME, Gordon C, Sogolow E, Lapin P, Bradley EH. Fall-risk evaluation and management: challenges in adopting geriatric care practices. Gerontologist. 2006;46:717-25.

45. Drickamer MA, Levy B, Irwin KS, Rohrbaugh RM. Perceived needs for geriatric education by medical students, internal medicine residents and faculty. J General Intern Med. 2006;21:1230-4.

46. Bunn F, Dickinson A, Barnett-Page E, McInnes E, Horton K. A systematic review of older people's perceptions of facilitators and barriers to participation in falls-prevention interventions. Ageing Soc. 2008;28:449-72.

47. Braun BL. Knowledge and perception of fall-related risk factors and fall-reduction techniques among community-dwelling elderly individuals. Phys Ther. 1998;78:1262-76. 
48. Bagge M, Tordoff J, Norris P, Heydon S. Older people's attitudes towards their regular medicines. J Prim Health Care. 2013;5:234-42.

49. Masud T, Blundell A, Gordon AL, Mulpeter K, Roller R, Singler $\mathrm{K}$, et al. European undergraduate curriculum in geriatric medicine developed using an international modified Delphi technique. Age Ageing. 2014;43:695-702.

50. Tinetti ME, Baker DI, King M, Gottschalk M, Murphy TE, Acampora $\mathrm{D}$, et al. Effect of dissemination of evidence in reducing injuries from falls. N Engl J Med. 2008;359:252-61.

51. Parekh N, Ali K, Davies K, Rajkumar C. Can supporting health literacy reduce medication-related harm in older adults? Ther Adv Drug Saf. 2018;9:167-70.

52. Cherubini ABR, Ferrucci L, Marchionni N, Studenski S, Vellas B. Clinical trials in older adults. Oxford: Wiley-Blackwell; 2015.

53. European Network of Centres for Pharmacoepidemiology and Pharmacovigilance. ENCePP Guide on Methodological Standards in Pharmacoepidemiology. 2017. http://www.encepp.eu/stand ards_and_guidances/methodologicalGuide.shtml. Accessed 14 May 2018.
54. International Society for Pharmacoepidemiology. Guidelines for Good Pharmacoepidemiology Practices (GPP). 2015. https ://www.pharmacoepi.org/resources/policies/guidelines-08027/. Accessed 14 May 2018.

55. Lamb SE, Jorstad-Stein EC, Hauer K, Becker C. Development of a common outcome data set for fall injury prevention trials: the prevention of falls network Europe consensus. J Am Geriatr Soc. 2005;53:1618-22.

56. Lavan A, Eustace J, Dahly D, Flanagan E, Gallagher P, Cullinane $S$, et al. Incident adverse drug reactions in geriatric inpatients: a multicentred observational study. Ther Adv Drug Saf. 2017;9:13-23.

57. WHO. The use of the WHO-UMC system for standardised case causality assessment. http://www.who.int/medicines/areas /quality_safety/safety_efficacy/WHOcausality_assessment.pdf. Accessed 8 May 2018.

58. Pit SW, Byles JE, Henry DA, Holt L, Hansen V, Bowman DA. A quality use of medicines program for general practitioners and older people: a cluster randomized controlled trial. Med J Aust. 2007; 187:23-30.

\section{Affiliations}

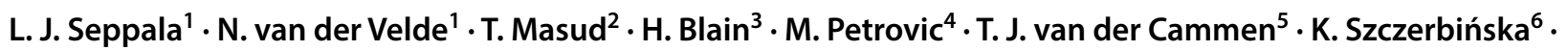

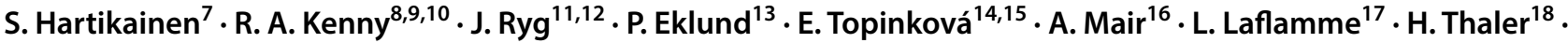
G. Bahat ${ }^{19} \cdot$ M. Gutiérrez-Valencia ${ }^{20} \cdot$ MA Caballero-Mora ${ }^{21} \cdot$ F. Landi ${ }^{22} \cdot$ M. H. Emmelot-Vonk ${ }^{23}$ on behalf of the EuGMS Task and Finish Group on Fall-Risk-Increasing Drugs · A. Cherubini ${ }^{24} \cdot$ J. P. Baeyens ${ }^{25,26} \cdot$ A. Correa-Pérez ${ }^{27}$. A. Gudmundsson ${ }^{28,29} \cdot$ A. Marengoni ${ }^{30} \cdot$ D. O'Mahony ${ }^{31,32}$ - N. Parekh ${ }^{33}$ - F. E. Pisa ${ }^{34,35}$. C. Rajkumar ${ }^{36} \cdot$ M. Wehling $^{37}$. G. Ziere ${ }^{38,39}$ on behalf of the EuGMS Special Interest Group on Pharmacology

1 Department of Internal Medicine, Section of Geriatric Medicine, Amsterdam Public Health Research Institute, Amsterdam UMC, University of Amsterdam, Meibergdreef 9, 1105AZ Amsterdam, The Netherlands

2 Nottingham University Hospitals NHS Trust, Nottingham, UK

3 Department of Internal Medicine and Geriatrics, University Hospital of Montpellier, Montpellier University, Euromov, France

4 Department of Internal Medicine (Geriatrics), Ghent University, Ghent, Belgium

5 Faculty of Industrial Design Engineering, Delft University of Technology, Delft, The Netherlands

6 Unit for Research on Aging Society, Department of Sociology of Medicine, Epidemiology and Preventive Medicine Chair, Faculty of Medicine, Jagiellonian University Medical College, Krakow, Poland

7 School of Pharmacy, University of Eastern Finland, Kuopio, Finland

8 The Irish Longitudinal Study on Ageing (TILDA), Trinity College Dublin, Dublin 2, Ireland

9 Department of Medical Gerontology, School of Medicine, Trinity College Dublin, Dublin 2, Ireland

10 Falls and Syncope Unit, Mercer's Institute for Successful Ageing, St. James's Hospital, Dublin 8, Ireland

11 Department of Geriatric Medicine, Odense University Hospital, Odense, Denmark
12 Geriatric Research Unit, Department of Clinical Research, University of Southern Denmark, Odense, Denmark

13 Department of Computing Science, Umeå University, Umeå, Sweden

14 Department of Geriatrics and Gerontology, 1st Faculty of Medicine, Charles University, Prague, Czech Republic

15 Faculty of Health and Social Sciences, South Bohemian University, Česke Budějovice, Czech Republic

16 Effective Prescribing and Therapeutics, Health and Social Care Directorate, Scottish Government, Edinburgh, Scotland, UK

17 Department of Public Health Sciences, Karolinska Institutet, Tomtebodavägen 18A, Widerströmska huset, 17177 Stockholm, Sweden

18 Trauma Center Wien-Meidling, Kundratstrasse 37, 1120 Vienna, Austria

19 Istanbul Medical School, Department of Internal Medicine, Division of Geriatrics, Istanbul University, Capa, 34093 Istanbul, Turkey

20 Department of Health Sciences, Public University of Navarra (UPNA), Avda, Barañain s/n, 31008 Pamplona, Spain

21 Servicio de Geriatría, Hospital Universitario de Getafe and CIBER de Fragilidad y Envejecimiento Saludable, Getafe, Madrid, Spain

22 Department of Gerontology, Neuroscience and Orthopedics, Catholic University of the Sacred Heart, Rome, Italy 
23 Department of Geriatrics, University Medical Center Utrecht, Utrecht University, Utrecht, The Netherlands

24

Geriatria, Accettazione geriatrica e Centro di ricerca per l'Invecchiamento, Italian National Research Center on Aging (INRCA), Ancona, Italy

25 University of Luxembourg, Ezch-sur-Alzette, Luxembourg

26 AZ Alma, Eeklo, Belgium

27 Servicio de Geriatría, Hospital Universitario Ramón y Cajal (IRYCIS), Madrid, Spain

28 Landspitali University Hospital, Reykjavik, Iceland

29 Faculty of Medicine, University of Iceland, Reykjavik, Iceland

30 Department of Clinical and Experimental Science, University of Brescia, Brescia, Italy

31 Department of Geriatric Medicine, Cork University Hospital, Cork, Ireland

32 Department of Medicine, University College Cork, Cork, Ireland
33 Academic Department of Geriatric Medicine, Brighton and Sussex Medical School, Brighton, Sussex, UK

34 Department of Clinical Epidemiology, Leibniz Institute for Prevention Research and Epidemiology-BIPS, Bremen, Germany

35 Institute of Hygiene and Clinical Epidemiology, University Hospital of Udine, Udine, Italy

36 Department of Elderly Medicine, Brighton and Sussex University Hospitals NHS Trust, Sussex, UK

37 Institute of Clinical Pharmacology Mannheim, University of Heidelberg, Heidelberg, Germany

38 Department of Internal Medicine, Erasmus MC, University Medical Centre Rotterdam, Rotterdam, The Netherlands

39 Department of Epidemiology, Erasmus MC, University Medical Centre Rotterdam, Rotterdam, The Netherlands 